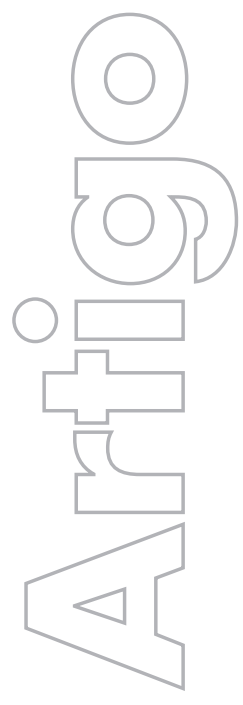

revista

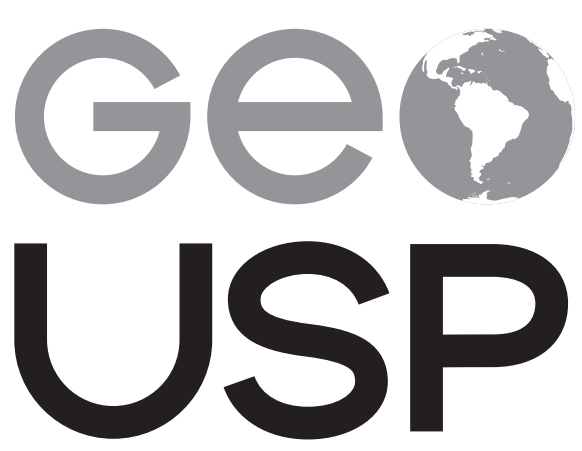

espaço e tempo

Volume $20 \bullet n^{\circ} 3(2016)$

ISSN 2179-0892
A produção do pensamento sobre a metrópole e o metropolitano pela escola de geografia urbana de São Paulo: o lugar de Sandra Lencioni

Eudes Leopoldo USP

p. $498-517$

Como citar este artigo:

LEOPOLDO, E. A produção do pensamento sobre a metrópole e o metropolitano na escola de geografia urbana de São Paulo: o lugar de Sandra Lencioni. Geousp - Espaço e Tempo (Online), v. 20, n. 3, p. 498-517, mês. 2016. ISSN 2179-0892.

Disponível em: <http://www.revistas.usp.br/geousp/issue/ view/6465>. doi: http://dx.doi.org/10.11606/issn.2179-0892. geousp.2014.84539.

\section{(c) (1) $(9$}

Este artigo está licenciado sob a Creative Commons Attribution 4.0 License. 


\title{
A produção do pensamento sobre a metrópole e o metropolitano pela escola de geografia urbana de São Paulo: o lugar de Sandra Lencioni
}

\section{Resumo}

A chamada escola de geografia brasileira pode ser considerada não uma escola nacional clássica, mas "uma escola com escolas". Nessa perspectiva, compreende-se a constituição da escola de geografia urbana de São Paulo como uma das principais correntes da geografia brasileira, desenvolvida com base num pensamento sobre a cidade e o urbano que se desloca para um pensamento sobre a metrópole e o metropolitano. Entre seus expoentes, destaca-se uma síntese das contribuições científicas de Sandra Lencioni, especialmente sobre a teoria da região e a problemática metropolitana e seus aportes à construção da escola de geografia urbana de São Paulo, à constituição da geografia brasileira e à produção do conhecimento geográfico universal.

Palavras-chave: Região. Metrópole. Metropolização. Sandra Lencioni. Escola de geografia urbana de São Paulo.

\section{The production of thought about the metropolis and the metropolitan by São Paulo school of urban geography: the place of Sandra Lencioni}

\begin{abstract}
The called school of Brazilian geography cannot be considered as a classic national school, but as "a school with schools". Therefore, we understand the constitution of São Paulo school of urban geography as one of the most important currents in the Brazilian school of geography based on the production of a thought about the city and the urban, which moves to a thought about the metropolis and the metropolitan. Among the exponents, we stand out a synthesis of scientific contributions of Sandra Lencioni, especially about the theory of region and metropolitan problematic, and his inputs to the construction of the São Paulo school of urban geography, the constitution of the Brazilian geography and the production of universal geographical knowledge.
\end{abstract}


Keywords: Region. Metropolis. Metropolization. Sandra Lencioni. São Paulo school of urban geography.

\section{Introdução}

"A Sandra é minha amiga querida, ela é muito rigorosa e inteligente" - professor José Borzacchiello responde à minha pergunta sobre o perfil da geógrafa que instigava minhas ideias, durante um intervalo de sua disciplina na pós-graduação em geografia (Fortaleza, 2011). "Você poderia fazer o doutorado com a Sandra, é a mais importante referência na geografia brasileira sobre a problemática metropolitana" - professora Zenilde Amora me indaga em uma conversa científica e prospectiva na varanda de sua casa, emoldurada pelo mar de edifícios (Fortaleza, 2012). "Na universidade é necessário ter o emocional forte" - durante uma reunião de orientação em seu gabinete, professora Sandra Lencioni me alerta com sua generosa sabedoria sobre a necessidade de equilibrio e foco (São Paulo, 2013). "Você ainda não sabe, mas já migrou para São Paulo" - professora Sandra Lencioni me adverte sobre a nova relação que tenho com o mundo e sobre a adoção de São Paulo como lar, mesmo que temporária, em outra reunião de orientação (São Paulo, 2014). "Podemos fazer um simpósio, como acontece na geografia francesa, a Sandra merece!" - professora Ana Fani Carlos sugere ideias à homenagem e assim fomos construindo uma bela parceria na coordenação do Colóquio, que resultou em um emocionante momento da geografia brasileira (São Paulo, 2015).

Os flashbacks transcritos na epígrafe povoaram a reconstituição das reminiscências recentes durante o café da manhã cedo e solitário no dia posterior à realização do Colóquio Sandra Lencioni: trajetória intelectual, ocorrido no histórico anfiteatro da geografia da Universidade de São Paulo no dia 10 de março de 2016. A partir do reconhecimento das contribuições de Sandra Lencioni no nível da produção científica, formação, extensão e gestão, situadas em seu memorável percurso, tivemos a dimensão real da força e envergadura da geografia brasileira.

A potência da contribuição científica da geografia brasileira na produção do conhecimento geográfico mundial é evidente. Diferentes intelectuais nacionais contribuíram decisivamente para a construção de uma "matriz" de pensamento sobre os conceitos e processos espaciais a partir dos fenômenos estudados no Brasil e América Latina. Se fala, no limite, de uma escola brasileira de geografia, cuja base seria o pensamento de Milton Santos trabalhado tanto pelo que se convencionou chamar de geografia humana e geografia física quanto pelos que produzem uma crítica implícita ou explícita às suas ideias.

Pensando a relação da geografia brasileira com as escolas nacionais, Abreu (1996) dá margem à discussão de uma escola de geografia brasileira. $\bigcirc$ autor fala do relevante "peso das chamadas escolas nacionais" no "establishment geográfico mundial", entretanto verifica "uma crescente independentização das comunidades geográficas dos países não centrais" e o fim do 
tempo em que "os geógrafos dos países periféricos sentiam-se (ou eram coagidos a sentir-se) eternamente discípulos dos mestres europeus e norte-americanos" (Abreu, 1996, p. 41). Em seguida, Abreu (1996, p. 42) observa que "o Brasil parece ter sido um dos países em que essas mudanças mais se fizeram sentir" e conclui com duas constatações: "a geografia brasileira desenvolveu-se mais nesses últimos anos do que em toda sua história pregressa" e "é impossível analisar-se a geografia brasileira dessas últimas décadas sem reverenciar o trabalho de Milton Santos". Em um trabalho sobre as influências e os vínculos entre os geógrafos franceses e a geografia brasileira, Silva (2012) registra quando Jacques Lévy e Paul Claval confirmam a existência de uma escola brasileira de geografia, enquanto Yves Lacoste e Michel Rochefort são reticentes. A citação a Milton Santos como referência da geografia brasileira é unanimidade entre os geógrafos franceses mencionados (Silva, 2012). Tereza Salgueiro (1996, p. 140) é mais enfática e afirma que "é indiscutível que Milton Santos criou uma escola [...] que para além do Brasil irradia para os países vizinhos e para a península Ibérica”. A importância e influência decisiva do pensamento de Milton Santos e sua projeção internacional como referência da geografia brasileira podem até localizar o problema de certa unidade potencial do conhecimento geográfico brasileiro, que podemos denominar escola de geografia, embora talvez não determine uma escola nacional na definição frequente do termo.

Diversos geógrafos argumentam que a geografia brasileira ganhou um caráter plural, tornando-a assim mais rica. Desse modo, sem um claro fio condutor de estruturas argumentativas e procedimentos válidos para diversas formas de produzir conhecimento geográfico no território nacional, como as monografias regionais para o clássico exemplo da escola francesa de geografia, é possível falarmos de uma escola brasileira de geografia? Contudo, até que ponto é necessário ou vale à pena pensar no conhecimento geográfico brasileiro constituindo uma escola? Uma escola não pode também ter diversos modos de pensar a realidade, posto que em "uma análise mais acurada daquilo que se convencionou chamar escola pode revelar na verdade tratar-se de grupos mais ou menos definidos, diferenciado e que, em muitos casos, se opõem" (Silva, 2012, p. 28)? Ela não poderia ser caracterizada também pela multiplicidade de concepções de mundo, atualizando-se assim a noção de escola nacional? Os conceitos geográficos de espaço, território, região, paisagem e lugar, atualizados por expoentes da geografia brasileira, não poderiam ser o núcleo identificador e movente da escola brasileira de geografia? A sua existência não estaria mais relacionada à robustez e certa autonomia de seu legado teórico-metodológico, bem como à sua projeção e poder de influência e cooperação para além das fronteiras nacionais, do que ao consenso interno do seu modus operandi? Segundo Carlos (2002, p. 162), "a geografia brasileira ganha especificidade muito mais na medida em que os geógrafos se colocam como tarefa pensar refletir/revelar o mundo em que vivem [...] do que enquanto criador de correntes geográficas próprias" e, poderíamos acrescentar, de uma escola nacional de geografia própria.

Em última instância, houve a produção de diferentes modos de fazer e pensar a geografia no âmbito dos departamentos de geografia das universidades brasileiras, que alcançaram repercussões e influências com intensidades diferentes. Os rebatimentos das ideias de determinados geógrafos por um espectro mais amplo se expandiram, na medida em que os encontros regionais e nacionais da Associação dos Geógrafos Brasileiros (AGB) ganharam densidade e 
os programas de pós-graduação em geografia se difundiram e se fortaleceram, em especial, na quarta metade do século XX. Os expoentes dos mais importantes núcleos de massa crítica da geografia brasileira, sobretudo sediados no eixo Rio-São Paulo, passaram a fomentar ideias e teorias em um primeiro momento de certo modo convergente, diante da transição epistemológica da década de 1970, e em um segundo momento divergente, frente às novas correntes geográficas e influências filosóficas que diversificaram os métodos de produzir ciência, incluindo, em alguns casos, a própria negação do método. Assim, no limite, talvez não seja possível evidenciar uma escola brasileira de geografia, mas "uma escola com escolas".

Podemos assim falar da emergência de uma escola original constitutiva e produtora da escola brasileira de geografia, que é produto de uma situação geográfica e um contexto histórico. A transição epistemológica da geografia brasileira em direção ao materialismo dialético, deu lugar ao aprofundamento crítico dos trabalhos teórico-metodológicos e ao predomínio da geografia urbana, acompanhando também o curso da realidade. $\bigcirc$ Brasil se tornava praticamente cada vez mais urbano. Nesse movimento, constituiu-se uma das principais escolas da geografia brasileira: a escola de geografia urbana de São Paulo. Podemos dizer que esta escola compõe o que Saint-Clair da Trindade Júnior denominou Escola Uspiana de Geografia (EUG). ' As expoentes desta escola são Sandra Lencioni, Ana Fani Carlos, Amélia Luisa Damiani e Odette Seabra, ${ }^{2}$ que se tornaram cada vez mais ativas desde o Departamento de Geografia da Faculdade de Filosofia, Letras e Ciências Humanas da Universidade de São Paulo no processo de mudança qualitativa da geografia, no sentido de uma ciência mais obstinada a pensar as contradições espaciais em sua totalidade. $\bigcirc$ imperativo de uma transformação radical na sociedade brasileira e no mundo tornava-se uma necessidade utópica comum entre elas, um desafio pensado a partir da crítica à economia política do espaço e do pensamento sobre as metamorfoses da cidade e do urbano, da metrópole e do metropolitano.

Mantendo-se ligada lato sensu a este grupo intelectual, sem abrir mão de suas próprias ideias e desafios, Sandra Lencioni enveredou para questões sobre o alcance do regional, do urbano e do econômico na virada do século, levando até as suas últimas consequências. Ao mesmo tempo em que testemunha as bruscas mudanças ocorridas em quase meio século, Sandra Lencioni trabalha intensamente na produção e desenvolvimento de conceitos e temas, que revelem os novos conteúdos dos processos espaciais de seu tempo, no sentido da atualização do pensamento sobre a cidade e o urbano em direção ao pensamento sobre a metrópole e o metropolitano. A teoria da produção do espaço de Henri Lefebvre (1991) dinamizada pela categoria região é o eixo estruturante de sua produção científica. A partir da relação entre a geo-

1 Na mesa redonda "Contribuições à produção e formação acadêmica" no Colóquio Sandra Lencioni: trajetória intelectual (2016), ele aponta a existência da Escola Uspiana de Geografia (EUG). Na mesma mesa, Elisa Verdi situou o Departamento de Geografia da USP no contexto da ditadura civil-militar e a participação de professores, no período estudantes, em movimentos estudantis e evidenciou que em trabalhos da época "revela-se não apenas uma insatisfação, mas principalmente a busca por novas questões, abordagens, teorias e métodos para a geografia". É nesse contexto que emerge a escola de geografia urbana de São Paulo como uma das correntes protagonistas da virada da geografia dentro da EUG e, em extensão, da escola de geografia brasileira.

2 Não podemos esquecer de mencionar outros geógrafos urbanos críticos da Universidade de São Paulo como o próprio Milton Santos, Maria Adélia de Souza, Maria Laura Silveira, Amália Inês Lemos, Francisco Capuano Scarlato, Margarida de Andrade, entre outros, que desenvolveram contribuições científicas a partir da segunda metade do século passado e que são referências intelectuais. Os quatro primeiros participam de uma corrente específica da geografia urbana, a partir da teoria santista, de grande projeção nacional, latino-americana e mundial. 
grafia regional, geografia urbana e geografia econômica e para além delas, portanto sem cair na vala comum da crescente especialização científica que empurra enorme parcela dos estudiosos para o enclausuramento orbital de suas análises, Sandra Lencioni contribui para a construção da escola de geografia urbana de São Paulo e atualização do pensamento geográfico.

Assim, objetiva-se compreender o lugar das ideias de Sandra Lencioni na produção do pensamento sobre a cidade e o urbano em direção ao pensamento sobre a metrópole e o metropolitano pela escola de geografia urbana de São Paulo. $\bigcirc$ movimento do pensamento se fundamenta na problematização das publicações das expoentes, em especial de Sandra Lencioni. Dividimos a exposição em dois momentos. Inicialmente, tratamos das bases teórico-metodológicas da escola de geografia urbana de São Paulo, ao mesmo tempo em que apresentamos as diferenças e nuances de cada uma de suas expoentes. Em seguida, discutimos a contribuição científica de Sandra Lencioni com relação à potência da teoria da região e à redescoberta da metrópole e do metropolitano. A tentativa é compor minimamente uma síntese das ideias de Sandra Lencioni, especialmente sobre a teoria da região e a problemática metropolitana, e seus aportes à construção da escola de geografia urbana de São Paulo, à constituição da geografia brasileira e à produção do conhecimento geográfico universal.

\section{A escola de geografia urbana de São Paulo}

Os cursos de graduação e pós-graduação em geografia da Universidade de São Paulo foi a usina gerativa da escola de geografia urbana de São Paulo. Nas décadas de 1970-80, os debates nas disciplinas de graduação e pós-graduação permitiram o compartilhamento de ideias, a aproximação cotidiana e a comunhão de utopias das precursoras ainda como estudantes. Antônio Carlos Robert de Moraes e Wanderley Messias da Costa também conviveram com as expoentes da escola de geografia urbana de São Paulo, dividindo momentos de formação. Wanderley Messias da Costa ${ }^{3}$ expressa bem a relação acadêmica e os debates acalorados nas disciplinas cursadas e aponta ainda o quadro de verdadeiros mestres com quem eles tiveram o prazer de aprender os fundamentos da geografia como Pasquale Petrone, Léa Goldenstein, Carlos Augusto de Figueiredo Monteiro e Aziz Ab'Saber.

Outro espaço de desenvolvimento intelectual das expoentes, para além dos domínios formais da formação universitária, foi o grupo de estudos sobre Karl Marx e Henri Lefebvre de José de Souza Martins, que teve duração de quase 20 anos, de 1975 até 1987. ${ }^{4}$ Ressalte-

3 Mesa redonda "Trajetória na geografia da FFLCH: depoimentos", Colóquio Sandra Lencioni: trajetória intelectual (2016).

4 próprio coordenador do grupo de estudos, José de Souza Martins (1996, p. 10), diz na apresentação do livro Henri Lefebure e o retorno à dialética que: "organizei em 1976 um seminário semanal sobre a obra de Karl Marx. No nosso seminário matutino das sextas-feiras, foi lida, durante doze anos, quase toda a obra de Marx. Encerrada essa etapa, decidimos em conjunto que ela deveria ter desdobramento e continuidade na leitura de um marxista contemporâneo de envergadura clássica. $\bigcirc$ autor que melhor corresponde a essa expectativa é Lefebvre. [...]. O colóquio A Aventura Intelectual de Henri Lefebvre constitui-se no ponto alto dessa experiência de dezoito anos do nosso seminário, que com ele se encerrou". O livro é produto do simpósio mencionado e conta com o texto de Odette Seabra A insurreição do uso (1996) e de Ana Fani Carlos sobre A mundialidade do espaço (1996). No cerne da diferença lefebvriana entre propriedade e apropriação, Seabra (1996) reconstitui teoricamente o uso como resíduo e possibilidade revolucionária, apontando para o não trabalho, em direção à obra. Já Carlos (1996) pensa a problemática espacial a partir da mundialidade, discutindo a primazia do espaço sobre o tempo, o Estado em seu processo de dominação global e a produção de centralidades a partir da tríade lefebvriana homogeneização-fragmentação-hierarquização. Sandra Lencioni participou intensamente 
-se que Marx e Lefebvre são as referências teórico-metodológicas estruturantes da escola de geografia urbana de São Paulo, sendo denominada também de corrente marxista-lefebvriana. Desse modo, o grupo de estudos potencializou as escolhas e caminhos de tal escola.

Durante este período de formação, apareceram os trabalhos pioneiros que sinalizam a escola, que são as dissertações de mestrado de Ana Fani Carlos e Odette Seabra de 1979, um artigo apresentado no 40 Encontro Nacional dos Geógrafos de 1981 e dois artigos científicos apresentados na Reunião Cultural em São Paulo da AGB em 1980 e publicados em 1982 na revista Borrador, os três últimos de autoria coletiva de Sandra Lencioni e Ana Fani Carlos. Ana Fani Carlos (1979) desenvolve a ideia de que a organização do espaço se fundamenta no modo de produção de um dado tempo histórico, portanto no modo de produção capitalista o resultado é um espaço capitalista, que deriva, sob o predomínio da reprodução das relações sociais de produção capitalistas, em um produto alienado, cuja expressão máxima é a metrópole. Já Odette Seabra (1979) elucida os enigmas que rondam a expansão das segundas residências e turismo no litoral, evidenciando as novas formas de uso e ocupação do solo em Santos, dominado por demandas sediadas, sobretudo, em São Paulo. Em seguida, Sandra Lencioni e Ana Fani Carlos definem pressupostos ativos na reflexão da escola de geografia urbana de São Paulo. Primeiramente, Carlos e Lencioni (1981) definem historicamente o processo de apropriação do espaço mediatizado pela relação de propriedade. Em seguida, Lencioni e Carlos (1982) discutem os alcances e os limites do espaço geográfico em relação ao meio geográfico e pensam a mercadoria-espaço em sua (in)finitude e como um "produto específico" por não ser composto necessariamente por trabalho objetivado e pela sua dialética permanente com "o substrato físico natural terrestre", exemplificando a partir do espaço metropolitano paulista. Posteriormente, Carlos e Lencioni (1982) problematizam a categoria Formação Econômica da Sociedade (FES) como um movimento do pensamento imprescindível para compreensão do espaço geográfico e como um processo "supranacional" e mais abrangente, pois alcança tanto a estrutura quanto a superestrutura. A procedência da escola de geografia urbana de São Paulo está claramente vinculada à uma abordagem geográfica crítica e, no limite, aos desdobramentos desiguais da reprodução da metrópole, que ilumina novos caminhos teóricos e práticos. As principais influências teórico-metodológicas fundadoras da escola de geografia urbana de São Paulo são:

- $\bigcirc$ materialismo dialético de Karl Marx;

- A teoria da produção do espaço de Henri Lefebvre;

- A potência da geografia crítica de David Harvey, Milton Santos e Yves Lacoste; e

- A sociologia marxista paulistana de José de Souza Martins e Francisco de Oliveira.

método dialético desenvolvido pela concepção materialista da história permitiu o desvendamento do trabalho como a substância contraditória do valor (Marx, 1985), que derivou os conceitos marxianos de acumulação do capital, mais-valia, valor de uso e valor de troca, trabalho socialmente necessário, fetichismo da mercadoria e alienação do homem, fundamentos teóricos da escola de geografia urbana de São Paulo. A contribuição capital de Henri Lefebvre

do grupo de estudos de José de Souza Martins. Em suas palavras, "ao final dos longos anos em que nos reuníamos às sextas-feiras pela manhã, semestre sim, semestre não, deixei de participar do seminário final e do projeto do livro", posto que "estava em viagem no exterior, procedendo à minha pesquisa de pós-doutorado" (Lencioni, 2006b, p. 21). 
(1972, 2001, 1991) sobre a vida cotidiana, o espaço urbano e o direito à cidade, as tríades espaço-temporais, atualizando e superando a obra de Marx, em direção a uma crítica à economia política do espaço, também foi central na constituição dessa corrente.

Realizando uma crítica e um balanço da geografia, Carlos (2002, p. 167) é categórico ao afirmar que "na direção oposta ao abandono do marxismo por uma parte dos antigos marxistas há, também, um conjunto grande de trabalhos que se propuseram a fazer uma crítica do marxismo por dentro", em outras palavras "a leitura crítica do legado de Marx como, por exemplo, é proposta por Henri Lefebvre, parece-nos um caminho profícuo - que funda uma análise, hoje, sobre a cidade e o urbano no Brasil”. Já Damiani (2009, p. 326), após fazer referência à revolução epistemológica da geografia rumo a uma perspectiva crítica e marxista, também aponta que "uma nova direção deste aporte chega à geografia urbana como conhecimento da produção do espaço, pela via lefebvriana, mais diretamente no Brasil, com a escola da USP". Fica claro pela explanação das suas próprias bases pelas expoentes e por seus trabalhos publicados que a escola de geografia urbana de São Paulo tem como fundamentos centrais as obras de Karl Marx e Henri Lefebvre.

Sem dúvida, os autores dos clássicos da geografia que corroboraram com sua transição também tiveram influência expressiva sobre os caminhos das expoentes. David Harvey com A justiça social e a cidade (1980), Milton Santos com Por uma geografia nova (1978) e Yves Lacoste com A geografia: isso serve, em primeiro lugar, para fazer a guerra (1988) dinamitaram as concepções tradicionais da geografia, revolucionando seu corpus científico. $\bigcirc$ espaço relacional, as rendas urbanas, a circulação do excedente (Harvey, 1980), a crítica à geografia colonial e matemática, o espaço como instância social, a unicidade do lugar (Santos, 1978), a espacialidade diferencial, a geografia como saber estratégico e a crise da geografia (Lacoste, 1988) são perspectivas que permeiam os trabalhos desenvolvidos pela escola de geografia urbana de São Paulo.

O campo de estudos sociológicos marxistas da Universidade de São Paulo é também uma de suas chaves mais evidentes. José de Souza Martins, Francisco de Oliveira e, acrescentaríamos também, Florestan Fernandes são sociólogos que iluminaram as perspectivas teóricas e práticas das expoentes. Em especial, José de Souza Martins influenciou decisivamente a perspectiva da produção da centralidade de São Paulo a partir da economia do café e da industrialização, que revelou a própria formação contraditória do Brasil moderno. A concepção de que o capitalismo engendra e reproduz relações não capitalistas de produção, a acumulação do capital na economia do café e na industrialização de São Paulo, explicitados por Martins (1986), são estruturantes nas análises das expoentes. Sem dúvida, a constituição histórica do desenvolvimento regional desigual brasileiro a partir do desenvolvimento das burguesias e do Estado capitalista, especialmente a transição do domínio dos "barões do café" para a "nova burguesia industrial" na chamada " 'região' industrial de São Paulo", desenvolvido por Oliveira (1977), também são processos referenciais. A gênese do desenvolvimento capitalista brasileiro a partir da constituição de uma "democracia burguesa" examinado por Fernandes (1976), desviando-se a teoria da dependência, de algum modo insere-se na compreensão da escala nacional em sua relação com o mundo pela referida corrente.

Podemos citar como influência também a própria escola francesa de geografia, que está presente desde o primeiro momento na formação em 1934 do curso superior de geografia da Universidade de São Paulo, o primeiro do Brasil, com Pierre Monbeig e Pierre Deffontaines (Silva, 2012). A influência por exemplo de um geógrafo francês como Pierre George é explícita, um dos autores 
diversas vezes referenciado pelas expoentes, pois contribuiu a partir das contingências de seu tempo histórico com inúmeras abordagens inovadoras à compreensão da relação espaço e sociedade. Bem como, a geografia paulistana "clássica", que inclusive é composta de professores e orientadores que participaram da formação das expoentes, como Léa Goldenstein, Nice Lecocq Müller, Armando Corrêa da Silva e Manoel Seabra. ${ }^{5}$ Wanderley Messias da Costa fala que as expoentes fazem parte de uma "geração de transição", "geração pós-últimos catedráticos", que substituíram os quadros citados. ${ }^{6}$ No Quadro 1, apresentam-se as relações de orientação na pós-graduação das expoentes. Assim, a escola de geografia francesa e a geografia paulistana "clássica" contribuíram para o aprofundamento do rigor científico, da disciplina acadêmica, da compreensão dos conceitos e categorias "geográficas" e da importância dos trabalhos de campo pela escola de geografia urbana de São Paulo.

\section{Quadro 1 - Genealogia intelectual da escola de geografia urbana de São Paulo}

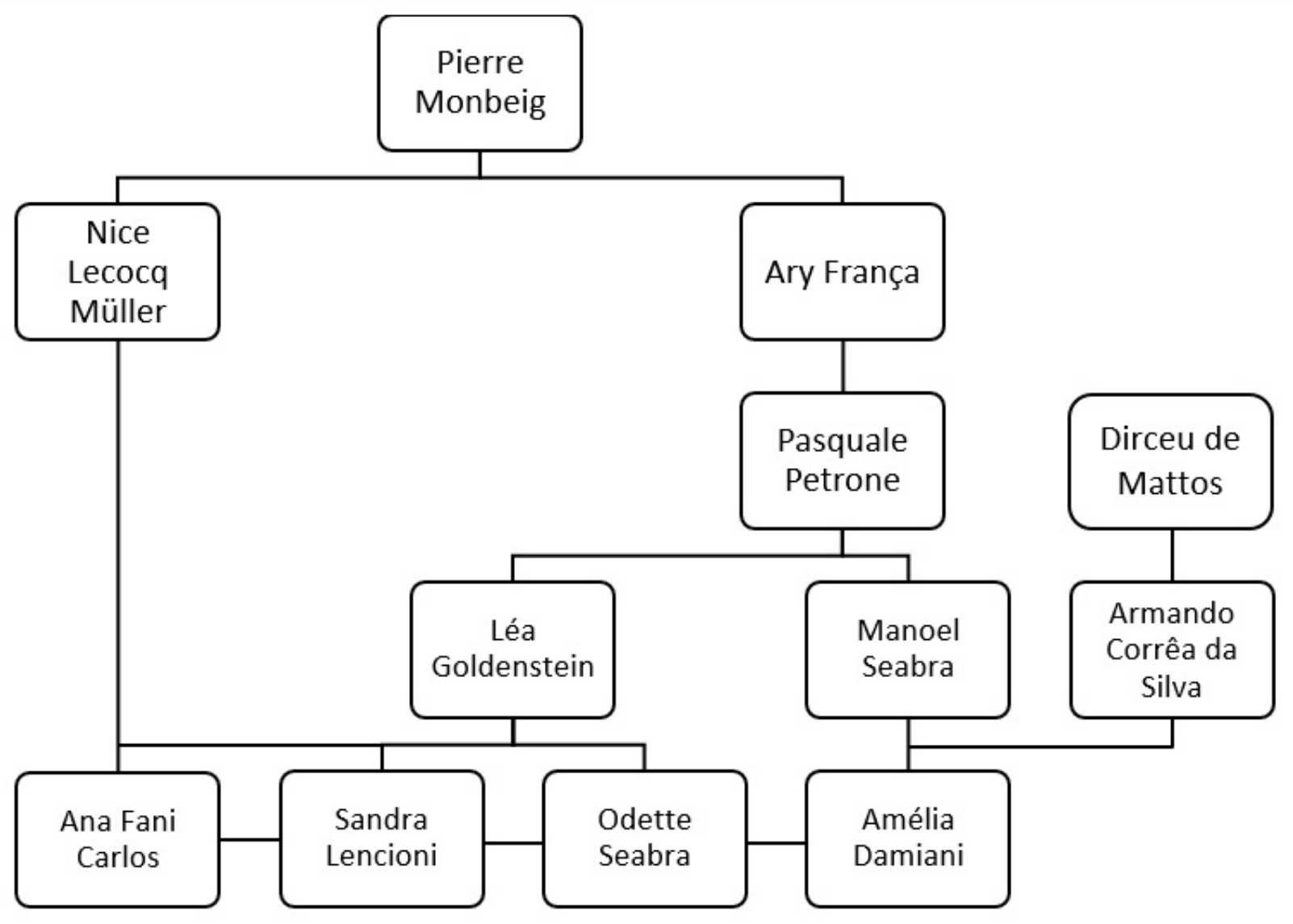

organização: Eudes Leopoldo (2016).

Diante dessas vinculações, as intelectuais fundadoras desta escola foram umas das protagonistas da revolução teórica na geografia e, ao mesmo tempo, da produção do pensamento sobre a cidade e o urbano, que se desloca para um pensamento sobre a metrópole e o metropolitano. A nosso ver, as chaves teóricas mais desenvolvidas e trabalhadas pelas precursoras

5 Léa Goldenstein orientou o mestrado de Sandra Lencioni, o doutorado de Ana Fani Alessandri Carlos e o mestrado e doutorado de Odette Seabra; Nice Lecocq Müller orientou o mestrado de Ana Fani Alessandri Carlos; Armando Corrêa da Silva orientou o mestrado de Amélia Damiani, e Manoel Seabra orientou o doutorado de Amélia Damiani.

6 Mesa redonda "Trajetória na geografia da FFLCH: depoimentos". 
da geografia urbana de São Paulo são: metropolização do espaço e região da metrópole desconcentrada - Sandra Lencioni; reprodução do espaço urbano e financeirização da metrópole - Ana Fani Carlos; urbanização crítica e colonização do cotidiano - Amélia Luisa Damiani; formação da metrópole e negação do bairro - Odette Seabra.

A escola de geografia urbana de São Paulo delineia um projeto de longo prazo, cuja base é um pensamento sobre a cidade e o urbano, que se move para um pensamento sobre a metrópole e o metropolitano. Emprega-se escola no sentido problematizado anteriormente, não como um espaço homogêneo de construção e difusão de ideias, mas também como espaço de diferenças, de concepções de mundo não necessariamente todo tempo convergentes, mas também tangenciais ou, no limite, dissonantes. Nesse sentido, situam-se as principais contribuições e diferentes fundamentações teóricas adquiridas pelas expoentes, de acordo com as relações tecidas com o seu tempo, com a comunidade científica e com os desafios levantados.

O pensamento de Ana Fani Carlos se move da organização do espaço à produção do espaço, da formação histórica da cidade à reprodução socioespacial da metrópole (Carlos, 1979, 1999, 2001, 2009, 2011). Atualmente, a perspectiva do predomínio do capital financeiro na reprodução do espaço urbano e, em última análise, da própria financeirização da metrópole, colocando em jogo as possibilidades e limites da vida cotidiana, se destaca em sua abordagem. ${ }^{7}$ A crítica à geografia, em especial, a David Harvey, bem como à vulgarização da concepção lefebvriana do direito à cidade e os reducionismos do planejamento urbano, apontando a construção de uma metageografia (Carlos, 2011), são uns de seus desafios mais emblemáticos.

Por sua vez, Amélia Damiani (2009, p. 327) evidencia uma "urbanização crítica" orientada pela reprodução da metrópole e para além dela, que subjaz a ideia de que "a produção do espaço urbano constituiria a atualização da grande maquinaria nos séculos XX e XXl”. O seu movimento do pensamento vai da relação centro-periferia à urbanização crítica, da colonização do cotidiano à construção de situações. ${ }^{8}$ Os desvios à geografia urbana, nomeadamente

7 Em sua dissertação de mestrado, Carlos (1979, p. 52) já aponta o financeiro como um momento importante para a produção das cidades ao dizer que "no mundo capitalista, o processo de regionalização está vinculado a todo um processo de desenvolvimento industrial e financeiro que ativa o crescimento das cidades", visto que "na cidade se concentra todo o poder de inovação do sistema, uma vez que ela concentra a atividade produtiva industrial e a financeira", assim "a grande cidade se apropria do excedente engendrado em seu território próximo". Ao analisar a Operação Urbana Faria Lima em São Paulo, Carlos (2001, p. 99) afirma que "a nova atividade econômica que se desenvolve na metrópole alia-se às necessidades de reprodução dos investimentos; é a ideia de que se produz uma mercadoria para o desenvolvimento de uma atividade econômica e ao mesmo tempo para o mercado financeiro como investimento, desenvolvendo o mercado de locação de escritórios por meio do desenvolvimento da indústria da construção civil". Dez anos depois, ela enfatiza que "a acumulação, tendo o espaço como elemento determinante, realiza-se também em outras escalas espaciais, fundamentalmente, na escala da cidade e da metrópole, além do plano global apontado por Harvey"; nessa direção, "a análise da metrópole paulistana hoje revela que o movimento de passagem da hegemonia do capital industrial ao capital financeiro a reproduz como negócio" (Carlos, 2011, p. 101). Observa-se claramente que as ideias de Ana Fani Carlos (2001; 2011) vão revelando a financeirização da metrópole e ela mesma como escala decisiva da acumulação do capital.

8 Damiani (2000, 1999a, 1999b) compreende que, na relação centro-periferia, se trata de um centro em movimento e periferias críticas, proletarizadas e caleidoscópicas, processo que situa a reprodução da força de trabalho. Em suas palavras, " a cidade sugere a presença de um proletariado crescente, envolvido na produção da urbanização", que envolve o "discernimento da metrópole como centro, que subordina as periferias que a rodeiam", posto que "a partir dela se generalizam procedimentos, normas, formas de produzir e reproduzir as cidades" (Damiani, 1999a, p. 124). Consoante à urbanização crítica, Damiani (2009, p. 309-312) afirma que ela se fundamenta em três grandes marcos processuais: (1) "a crise do trabalho, contida na crise do capital"; (2) "as cidades passam a constituir espaços privilegiados da produção mercantil do espaço, internalizando a metamorfose do capital produtivo em capital financeiro, incluindo o capital enquanto fictício"; (3) "esta profunda destituição da humanidade do homem é, ao mesmo tempo, a 
a Pierre George, seguindo por uma redescoberta da teoria e arte situacionista, em busca dos resíduos (lefebvrianos), dos relevos psicogeográficos (debordianos), move hodiernamente suas ideias. ${ }^{9}$

Outra expoente, Odette Seabra (2009, p. 422) chega à compreensão no século XXI que "a constituição real e formal da metrópole corresponde ao dilaceramento de formações pretéritas, sejam cidades, bairros ou subúrbios". O seu movimento do pensamento vai desvelando as contradições dos espaços dos lazeres povoados pelas categorias propriedade, preço e renda da terra, transbordando atualmente para a relação entre a formação da metrópole e a negação do bairro, mediado pelo modo de vida. ${ }^{10}$ Uma das propostas em desenvolvimento é pensar uma geografia cultural crítica, fundado na reprodução do espaço urbano e na crítica à vida cotidiana. ${ }^{11}$

Para concluir o esboço de um panorama preliminar deste verdadeiro projeto de geografia urbana, localiza-se a contribuição intelectual de Sandra Lencioni. Se tivermos que delimitar o caminho da totalidade de ideias de Sandra Lencioni, diríamos que se trata de um movimento do pensamento que vai da cidade pequena (lugar) à megalópole (megarregião), da relação cidadecampo à metropolização do espaço. ${ }^{12}$

As tríades lefebvrianas homogeneização-fragmentação-hierarquização e forma-função-estrutura são essenciais na construção de suas ideias, cujos fundamentos corroboram na construção da noção de reestruturação do espaço. A problemática das condições gerais de produção desenvolvida por Karl Marx e a discussão dos espaços metropolizados e não metropolizados de Bernard Kayser também tem uma forte influência em seu pensamento. A diferença entre concentração e centralização do capital, regime de acumulação patrimonial, temários desenvolvidos pela escola da regulação (Michel Aglietta, Alain Lipietz), assim como as abordagens regionais da chamada escola de geografia urbana de Los Angeles (Allen Scott, Edward Soja, Michael Storper, John Agnew), em especial o conceito de "cidade-região", são alcances teóricos diferenciais na produção de Sandra Lencioni. Atualmente, evidencia-se o desafio de problematizar o legado de Jean Gottmann e seus estudos sobre a megalópole.

'naturalização' do humano".

9 Evidenciam-se os limites e as possibilidades da obra de Pierre George para a relação espaço e população (Damiani, 1991, p. 47/54-55/68) e geografia urbana (Damiani, 2009, p. 324-325/330).

10 Para Odette Seabra (1996, 2009), no cotidiano encontram-se as chaves de construção de um novo mundo, o projeto de um outro espaço possível. Ela defende que "no cotidiano, inscrito e prescrito, no caminho da gestão total pelo Estado, os resíduos como dimensão de qualidade da existência permanecem intersticiais” (Seabra, 1996, p. 79). Segundo Seabra (2009), na metrópole, a vida de bairro como momento do cotidiano é cada vez mais negada e usurpada de seus referenciais. Logo, "a palavra bairro perde seu conceito", "o bairro estudado e todos os bairros guardam muito mais uma referência de localidade inscrita na metrópole e como um fragmento desta” (Seabra, 2009, p. 427). Levando as últimas consequências, evidencia que o processo de metropolização é o da própria formação da metrópole e, ao mesmo tempo, da negação do bairro (Seabra, 2009).

11 A relação entre modo de vida e modo de produção a partir da problemática da cultura na reprodução do espaço, com um diálogo aberto com o geógrafo cultural Denis Cosgrove, é desenvolvido por Seabra (2009, 2012).

12 Na discussão sobre a relação agricultura e urbanização, Lencioni (1985, p. 146) observa que "a urbanização do campo compreendida no movimento de reprodução do capital indica a contradição cidade campo, mas também a direção para superar essa contradição", na medida em que "o campo moderniza-se, consome mercadorias produzidas por processos industriais e desenvolve o assalariamento como principal forma de remuneração de sua força de trabalho". Assim, já se vislumbra, por meio da atualização da contradição capital-trabalho, limites da relação cidade-campo, que posteriormente será incorporada como momento da relação cidade-região. Nas palavras de Lencioni (2003, p. 35), "a dinâmica territorial paulista não pode ser mais apreendida tendo como referência a relação cidade-campo nos moldes tradicionais e clássicos dos estudos geográficos", posto que no "processo de metropolização do espaço é que reside a nova rede de relações que permite reconstituir, do ponto de vista teórico, a unidade entre cidade e região". 
É notório o seu grande esforço em elucidar as metamorfoses metropolitanas, econômicas e regionais. No campo da geografia urbana, Sandra Lencioni tem levantado ideias fundamentais para a compreensão das regiões metropolitanas e do processo de metropolização do espaço. Diante do primado da problemática metropolitana no plano mundial e, em particular, da criação do Estatuto da Metrópole no âmbito nacional, no sentido de evidenciar seus alcances e reduções, suas teses tornaram-se chaves para pensar o Brasil e o mundo. No domínio da geografia regional, é um dos principais estudiosos na área com destaque para seu clássico livro Região e geografia, em que trata a partir da categoria região do pensamento geográfico produzido (Lencioni, 1999a). Sem falar que o regional a permitiu revelar o mundo contemporâneo e aprofundar as contradições do espaço ao tencioná-lo com o metropolitano e o econômico. Na esfera da geografia econômica, sua dissertação de mestrado sobre a capitalização da agricultura e a urbanização do campo (Lencioni, 1985) e sua tese de doutorado que traz uma crítica fundamental às principais teorias vigentes sobre São Paulo na época como a "reversão da polarização", "desconcentração industrial" e "industrialização do interior" (Lencioni, 1991) redefinem novas possibilidades e tendências críticas de trabalho nesta área. Contudo, a potência de suas ideias está no movimento de seu pensamento em mergulhar em cada uma destas grandes áreas do conhecimento geográfico, sem se perder ou se guiar por nenhuma delas, posto que ao mesmo tempo as supera, em direção à compreensão da totalidade dos processos.

\section{O retorno da região e a redescoberta da metrópole e do processo de me- tropolização}

A região é o nexo categorial fundante da geografia como ciência moderna. Quando falamos em geografia regional, falamos da grande área célebre do pensamento geográfico, detentora das profundas tradições e das intensas metamorfoses do conhecimento geográfico institucionalizado, que se desenvolveu primeiramente como domínio da construção de monografias regionais com base no método positivista e na ideologia imperialista-colonialista, mas também como uma promissora perspectiva de unidade entre a geografia humana e a geografia física. No limite, a teoria da região seria o cerne da potência de toda a produção da geografia como ciência. ${ }^{13}$

Na geografia mundial, dois momentos de ruptura com o conceito de região são notados por Haesbaert (2010, p. 49), quando diz que "se a chamada geografia quantitativa representou o primeiro momento da morte e ressureição da região, o segundo viria com a geografia crítica de fundamentação marxista”. No segundo período de negação da região, a crítica de Lacoste

13 Lencioni (1999b, p. 203) defende que "desde a preocupação geográfica da Antiguidade há uma continuidade na formação de métodos e sistematizações do conhecimento geográfico com interesse na análise regional”. Com relação à institucionalização da geografia como ciência, Lencioni (1999a, p. 102) evidencia que "a maior expressão da geografia regional foi Paul Vidal de La Blache (1845-1918), sendo imprescindível para se compreender a força do paradigma regional na geografia conhecer algumas de suas ideias", posto que "até Vidal de La Blache, a geografia, na França, não se constituía num ramo autônomo do conhecimento que fizesse parte da História. Com ele é que a geografia atinge um status independente e se consagra como um ramo específico da ciência". Na mesma direção, Haesbaert (2010, p. 41) diz que "a força da geografia regional chegou a esse ponto, que ela foi erigida como fundamento paradigmático da disciplina", sendo que a geografia regional passou a ser "o núcleo-chave da geografia" e a região "o conceito mais pretencioso da geografia, 'síntese' dos múltiplos componentes do espaço geográfico”. Silveira (2006, p. 85) destaca que "ontem, o papel forte da razão na geografia, promessa do seu caminho para a cientificidade, fundou-se na herança do século das luzes, que ajudou a constituir uma disciplina em torno de ideias como região, gênero de vida, paisagem”. 
(1988, p. 62-63) é incisiva, no momento em que defende que "fruto do pensamento vidaliano, a 'região geógrafica', [...], se tornou um poderoso conceito-obstáculo", enquanto seria mais salutar "considerar a região como uma forma espacial de organização política", de acordo com sua própria origem etimológica. No entanto, Lacoste (1988, p. 77) reconhece que o mérito principal de Vidal de La Blache é o de ter evidenciado a partir de suas profundas monografias regionais, "a complexidade das interações que se estabeleceram no decurso da história, entre os fatos físicos e os fatos humanos", desenvolvendo a região como "a 'realidade geográfica' por excelência". Do ponto de vista teórico e empírico, é complicada a visão positivista e colonialista de Vidal de La Blache em Princípios de geografia humana (1954), mas não podemos negar certa generosidade de sua admirável descrição geográfica e a maneira pela qual reverencia os centros, denominados "centros de densidade", como "oficinas de civilização" (Vidal De la Blache, 1954, p. 84). A extensa obra lablachiana sobre a expansão e hegemonia evolucionista dos povos a partir da "totalidade" do conjunto de regiões é produzida sobre uma valsa interminável, tendo como base a região não como conceito, mas como movimento.

Apesar dos grandes períodos de crítica e ostracismo do conceito de região, que tentaram colocar em cheque sua validade e potência científica, apresentaram-se importantes grupos de scholars que reacenderam a chama da teoria da região e a atualizaram. Na década de 1960, o movimento da geografia ativa na França composto por Pierre George, Bernard Kayser, Yves Lacoste e Raymond Guglielmo coloca o desenvolvimento regional desigual no centro do debate geográfico, que fica claro nos textos sobre o papel do geógrafo e a potência da região (George, 1968); o conceito de região, sua estrutura e formação (Kayser, 1968); e a abordagem sobre a região como instrumento de ação política, em que se enfatiza os diversos casos de aplicação das políticas regionais no mundo (Kayser; George, 1968), todos publicados na obra A geografia ativa. Na Inglaterra, a partir do fim da década de 1970, Doreen Massey, Nigel Thrift, Ash Amin, John Allen e Allan Cochrane redefinem a região, em especial a partir de sua relação com o lugar, cujo fundamento é dado pelo trabalho de Massey (1978), que busca decifrar a relação entre as desigualdades regionais e a divisão espacial do trabalho. Na década de 1990, emergem as abordagens regionais da chamada escola de geografia urbana de Los Angeles, composta por Allen Scott, Edward Soja, Michael Storper, John Agnew, que ganhou mais notoriedade a partir da construção do conceito de "cidade-região global" (Scott et al., 2001) e, mais recentemente, com a perspectiva da "urbanização regional" (Soja, 2011, 2013). ${ }^{14}$ Pelos nomes envolvidos e suas respectivas escolas não fica difícil demonstrar a continuidade na descontinuidade da relevância da teoria da região na produção do conhecimento geográfico mundial, apesar de seus momentos de negação.

Na geografia brasileira, com a virada epistemológica na década de 1970, passou a predominar a categoria espaço e, nos anos 1990, o conceito de território. Apesar disso, o conceito de região continuou mais vivo do que nunca. Um dos mais destacados da teoria da região

14 Haesbaert (2010) define o movimento da geografia ativa como parte de uma "abordagem normativa", em que aparece "a região como instrumento de ação e/ou projeto de intervenção no real", já a escola de Londres e a escola de Los Angeles como constitutivas de uma "abordagem neomarxista", cuja ênfase é na descontinuidade da região e seu caráter de lugar. Sobre o movimento da geografia ativa, Lencioni (1999a, p. 141) aponta que ela "tinha como proposta a organização do espaço" a partir de certa "ilusão tecnocrática". 
na geografia brasileira é Sandra Lencioni, primeiramente com um trabalho apresentado no 40 Congresso Brasileiro de Geógrafos de 1984, em parceria com Ana Fani Carlos, sobre as discussões do regional no Boletim Paulista de Geografia (Carlos; Lencioni, 1984); em seguida, com a tese sobre a região da metrópole desconcentrada (Lencioni, 1991); depois, com o livro sobre a construção da teoria da região na produção do conhecimento geográfico (Lencioni, 1999a); e, por fim, com os trabalhos sobre a cidade-região (Lencioni, 2003, 2006a, 2007) e a megarregião (Lencioni, 2015). Rogério Haesbaert também se destaca na temática da região e regionalização, inicialmente com uma proposta sobre a regionalização do Rio Grande do Sul a partir da relação centro-periferia (Haesbaert, 1983); depois, com o desenvolvimento da noção de "rede regional" (Haesbaert, 1998); e, atualmente, com a construção do conceito de região como "artefato" (Haesbaert, 2010). Há também outros importantes geógrafos brasileiros como Corrêa (1986) e Gomes (1995), que realizaram um enorme esforço de compreensão do conceito de região pelos diferentes momentos da história do pensamento geográfico.

Fica evidente que o conceito de região tanto na geografia mundial quanto na geografia brasileira sempre esteve presente e vivo, com diferentes intensidades, atualizando-se e sedimentando novos horizontes ao pensamento geográfico. A contribuição científica de Sandra Lencioni sobre a questão regional é tributária deste contexto histórico.

Na tese sobre a região da metrópole desconcentrada, já se apresenta o cerne do conceito de região sempre em movimento, que posteriormente será mais detalhado em Região e geografia. A metrópole desconcentrada ganha a corporeidade de uma região de outra natureza, que não se reduz à região metropolitana paulistana, mas há um processo de produção do espaço metropolitano, cujo resultado é uma região em expansão, que é ao mesmo tempo redimensionada e diferenciada internamente de modo permanente. "Os limites regionais são múltiplos, dinâmicos" (Kayser, 1968, p. 282), assim como as diferenciações e fragmentações internas da região, aponta a tese. A crítica às políticas regionais, que reforçaram a concentração industrial, é um dos grandes momentos da compreensão do desenvolvimento regional desigual. Lencioni (1991, p. 103) é enfática ao dizer que o "crescente empobrecimento e industrialização fracassada, como instrumento das políticas de desenvolvimento regional, marcaram duramente a realidade fazendo dos projetos de desenvolvimento regional verdadeiras miragens". A tradução das políticas regionais travestidas de políticas de desenvolvimento industrial e da produção de uma região com sede em São Paulo e construída a partir da centralização do capital e dispersão dos estabelecimentos industriais, constitui as bases da ideia de região como conceito dinâmico, em mediação com a totalidade das relações sociais de produção.

Em seguida, indo na contramão da proposta de Pierre George (1968, p. 33) que admite a necessidade de "definir e delimitar a região", Lencioni (1999a) trabalha as diferentes concepções de região e regionalização nas variadas correntes geográficas historicamente determinadas, sem se ater à construção de um conceito de região. Trata-se de uma obra que coloca em diálogo as grandes fronteiras dos estudos regionais no conhecimento geográfico, que ultrapassa a própria concepção de geografia como ciência. Na beleza de suas páginas, o livro sintetiza a categoria região, que é sempre mediatizada pela imagem de Cosmos. Durante a leitura, há uma sensação que o universo inteiro está, à sua maneira, presente no pensamento cumulativo e simultâneo sobre as regiões e na constituição das múltiplas e diversas regiões estabelecidas 
historicamente e confrontadas com as novas articulações espaciais e temporais advindas da chamada globalização. Lencioni (1999a, p. 194) conclui que "a escala regional, como escala intermediária de análise, como mediação entre o singular e o universal, pode permitir revelar a espacialidade particular dos processos sociais globais". Desse modo, a região se revela como "parte de uma totalidade" (Lencioni, 1999a, p. 198).

Após redefinir o conceito de região, atualizando-o como momento da totalidade, Lencioni $(2003,2006 a, 2007,2015)$ redescobre a descontinuidade como momento constitutivo e dinâmico das formas espaciais, passando a trabalhar com uma simultaneidade entre regiões metropolitanas e seu entorno. Trata-se de uma dialética da descontinuidade! No plano local, pensa a macrometrópole paulista como uma cidade-região, composta pelas regiões metropolitanas de São Paulo, Campinas, Baixada Santista, Vale do Paraiba e Litoral Norte, Sorocaba e as microrregiões urbanas integradas. No plano nacional, confere à megalópole brasileira em constituição a noção de megarregião, que integra a nebulosa metropolitana paulista com a carioca. A perspectiva regional abriu passagens para além de um pensamento sobre São Paulo como região metropolitana, a própria metrópole paulistana se espraia desmesuradamente e só se resolve cada vez mais numa rede de cidades, que ultrapassa inclusive o estado de São Paulo. Vale mencionar a investigação sobre dinâmicas metropolitanas para além do território nacional, enfocando as diferenças e similaridades entre as regiões metropolitanas de São Paulo, Buenos Aires e Santiago a partir da problemática da governança (Lencioni, 2008).

A cidade-região emerge como um momento teórico de atualização do debate sobre a macrometrópole paulista, já presente em sua tese sobre a centralização do capital e a desconcentração da metrópole de São Paulo (Lencioni, 1991). ${ }^{15}$ A cidade-região expressa não só uma forma urbana, mas a própria forma da divisão social e territorial do trabalho (Lencioni, 2007). As descontinuidades em suas diferentes faces são tratadas como constitutivas do próprio processo de formação da cidade-região e os limites fluidos e sempre em redefinição consoante à difusão crescente das formas e conteúdos da centralidade por um espaço cada vez mais amplo são movimentos claramente vinculados ao processo de constituição da cidade-região (Lencioni, 2006a). A cidade-região é pensada como uma das bases espaciais do processo de valorização do capital. Nesse sentido é utilizado o conceito de condições gerais de produção, que é o meio pelo qual se relaciona o processo imediato de produção e a produção e circulação do capital em geral.

A brilhante afirmação de que "na contemporaneidade, emergem novos arranjos e dinâmicas territoriais que não permitem manter a distinção entre a cidade e sua região, em termos consagrados na literatura, porque a cidade se tornou região" levou Lencioni (2006a, p. 69) a repensar a explosão da hierarquia piramidal clássica a partir das transformações entre o local, o regional e o global. A compreensão das redes e suas variadas possibilidades de conexão espacial

15 Lencioni (1991, p. 69) explica que "na reestruturação urbano-industrial do estado de São Paulo, a conurbação de cidades, o crescimento relativamente menor de algumas ou exacerbado de outras - como, por exemplo, o grande crescimento de Campinas -, não significa processos autônomos de metropolização. Ao contrário, são manifestações constitutivas da expansão metropolitana paulista, que se configura numa 'macrometrópole' que é reforçada, e não negada, pela dispersão". Aqui já se localiza certo desenvolvimento precoce do conceito de cidade-região para o caso paulista, que aparece ainda como macrometrópole. Sob influência da escola de geografia urbana de Los Angeles, Lencioni (2006a, 2007) emprega o conceito de cidade-região para denominar a extensa unidade espacial paulista. 
e temporal, que faz com que "alguns lugares se tornem próximos a lugares distantes, enquanto que lugares vizinhos podem conhecer poucas relações entre si” (Lencioni, 2006a, p. 70), foi importante neste desafio.

Assim, "cidade e região aparecem solidários" (Santos, 1965, p. 134), mais ainda, se metamorfoseiam um no outro e são crescentemente "os motores regionais da economia global" (Scott et al., 2001, p. 16). Desse modo, constitui-se a cidade-região, entrelaçada por redes e descontinuidades, como testemunho histórico da atualidade crítica do modo de produção capitalista. Do ponto de vista do plano imediato, não podia ser diferente, cada vez mais "desconfiamos do fato de estarmos vivendo em cidades" (Lencioni, 2014, p. 3), pois vivemos numa região (Lencioni, 2010).

A cidade-região paulista caminha a passos largos para a sua integração com a região metropolitana carioca e seu entorno. Assim, emerge a constituição de uma megalópole nacional, descrita e explicada por Lencioni (2003) a partir da problematização das descontinuidades, que se "desmancham" pelo movimento de integração megalopolitana. No sentido do rigor conceitual, dez anos depois Lencioni (2015) prefere empregar o termo "megarregião", advertindo sobre as diferenças entre a megarregião Rio-São Paulo e a megalópole na perspectiva gottmaniana, mas não descarta o uso deste referencial. Pelo contrário, o reconstitui como base teórica para tradução destas formas espaciais. ${ }^{16}$

Para Lencioni (2015, p. 61), a megarregião constitui "uma macroestrutura fortemente integrada pelo capital e pelo trabalho, na qual as cidades e os arredores estão bastante conectados, além de apresentar fortes vínculos com a dinâmica global". Ela vê no caso da megarregião Rio-São Paulo "o caráter supermetropolitano" que Gottmann (1957, p. 189) aponta originalmente para o caso de uma vasta área da costa litorânea do nordeste americano, mas também se refere às diversas diferenças que há entre ambas as situações e temporalidades. Lencioni (2015, p. 62) esclarece que a primeira diferença é que a megarregião apresenta "uma forma híbrida e não apenas linear", e outros dois aspectos enfatizam a importância da rede de circulação imaterial e das relações globais e não mais apenas dos eixos de circulação viária e dos vínculos internacionais do passado, assim como postulava a perspectiva gottmaniana, que é do início da segunda metade do século passado, quando havia o predomínio de outras variáveis e determinações. Hoje, a crescente simultaneidade entre globalização financeira, metropolização do espaço e regionalização da sociedade, cujo produto e condição é a "economia metropolitano-financeira" (Leopoldo, 2015), torna ainda mais imperativo o rigor conceitual para não cairmos em uma confusão epistemológica nem em ortodoxias fechadas.

Cada vez mais constituem-se cidades-região e megarregiões, que iluminam a crescente regionalização do mundo. Trata-se de uma verdadeira metropolização regional, que é a concentração e difusão dos conteúdos metropolitanos orientados pelo desenvolvimento regional desigual da reprodução das relações sociais de produção. Explicita Corrêa (1986, p. 44) que no modo de produção capitalista "o processo de regionalização se acentua, marcado pela simultaneidade dos processos de diferenciação e integração", apesar da ideologia da homogeneização

16 Lencioni (2015, p. 62) assinala que "podemos afirmar que a nebulosa urbana que estamos examinando [Rio-São Paulo] constitui uma megarregião. De certa forma, ela é uma megalópole, desde que se atualize esta terminologia e alguns elementos de seu conteúdo clássico, sendo agora vista como uma megalópole contemporânea". 
por conta dos imperativos da globalização. Ao mesmo tempo, a metropolização do espaço se acirra e ganha o plano da totalidade. Assim, "metropolização e regionalização apresentam unidade, pois o processo de metropolização, [...], se constitui também num processo de regionalização" (Lencioni, 2006a, p. 74).

\section{Metamorfoses metropolitanas, econômicas e regionais: considerações finais}

A trajetória intelectual de Sandra Lencioni é constituída por percursos não especializados, instigantes e desafiadores. Regiões de conhecimentos e regiões de vivências se entrecruzam e se confrontam.

A dialetização da descontinuidade, a atualização do temário regional, a ressignificação da metrópole e da aglomeração, a revelação da metropolização do espaço como processo global, a superação da relação cidade-campo e centro-periferia, o desenvolvimento das categorias econômicas marxistas a partir do olhar geográfico, a compreensão das redes e escalas espaciais, a problematização das tríades espaço-temporais lefebvrianas e a leitura das novas formas regionais em expansão são algumas luzes que trazem o trabalho de Sandra Lencioni. Geografia urbana, geografia regional e geografia econômica aparecem em suas discussões como sinalizadores, e não como cátedras dogmáticas do saber especializado.

Suas contribuições à construção da escola de geografia urbana de São Paulo são consideráveis. Permitem iluminar a unidade entre metropolização e regionalização, ao mesmo tempo em que situa a nova geografia econômica do modo de produção capitalista do século XXI, num robusto esforço de atualização do legado marxista-lefebvriano e do pensamento geográfico. Em suas ideias, se movem a transição do pensamento sobre a cidade e o urbano ao pensamento sobre a metrópole e o metropolitano.

\section{Referências}

ABREU, M. Sobre Milton Santos e sobre a crescente autoestima da geografia brasileira. In: SOUZA, M. (Org.). O mundo do cidadão, um cidadão do mundo. São Paulo: Hucitec, 1996. p. 35-48.

CARLOS, A. F. A. A condição espacial. São Paulo: Contexto, 2011.

A "ilusão" da transparência do espaço e a "fé cega" no planejamento urbano: os desafios de uma geografia urbana crítica. Cidades, São Paulo, v. 6, n. 10, 2009.

A Geografia brasileira, hoje: algumas reflexões. Terra Livre, São Paulo, v. 1, n. 18 , p. 161-178, 2002.

Espaço-tempo na metrópole: a fragmentação da vida cotidiana. São Paulo: Contexto, 2001.

"Novas" contradições do espaço. In: DAMIANI, A.; CARLOS, A. F. A.; SEABRA,

O. (Org.). O espaço no fim de século: a nova raridade. São Paulo: Contexto, 1999.

A mundialidade do espaço. In: MARTINS, J. S. (Org.). Henri Lefebvre e o retorno à dialética. São Paulo: Hucitec, 1996. p. 121-134. 
Reflexões sobre o espaço geográfico. Dissertação (Mestrado em Geografia Humana) - Faculdade de Filosofia, Letras e Ciências Humanas, Universidade de São Paulo, São Paulo, 1979.

CARLOS, A. F. A.; LENCIONI, S. O "regional" no Boletim Paulista de Geografia. In: CONGRESSO BRASILEIRO DE GEÓGRAFOS, 4., 1984, São Paulo. Anais... São Paulo: AGB, 1984.

A categoria "Formação econômica da sociedade" na análise geográfica. Borrador Teoria e Método, São Paulo, n. 1, p. 11-18, 1982.

A apropriação capitalista do espaço geográfico. In: ENCONTRO NACIONAL

DE GEÓGRAFOS, 4., 1981, Rio de Janeiro. Anais... Rio de Janeiro: AGB, 1981.

CORRÊA, R. L. Região e organização espacial. São Paulo: Ática, 1986.

DAMIANI, A. L. Urbanização crítica e produção do espaço. Cidades, São Paulo, v. 6, n. 10, 2009.

A metrópole e a indústria: reflexões sobre uma urbanização crítica. Terra Livre, São Paulo, n. 15, p. 21-38, 2000.

A crise da cidade: os termos da urbanização. In: DAMIANI, A. L.; CARLOS, A. F;

SEABRA, O. C. L. (Org.). O espaço no fim de século: a nova raridade. São Paulo: Contexto, 1999a.

. As contradições do espaço: da lógica (formal) à (lógica) dialética, a propósito do espaço. In: DAMIANI, A. L.; CARLOS, A. F; SEABRA, O. C. L. (Org.). O espaço no fim de século: a nova raridade. São Paulo: Contexto, 1999b.

População e geografia. São Paulo: Contexto, 1991.

FERNANDES, F. A Revolução Burguesa no Brasil: ensaio de interpretação sociológica. Rio de Janeiro: Zahar, 1976.

GEORGE, P. Problemas, doutrina e método. In: GEORGE, P. et al. (Org.). A geografia ativa. São Paulo: Difel, 1968.

GOMES, P. O conceito de região e sua discussão. In: CASTRO, I.; CORRÊA, R.; GOMES, P. (Org.). Geografia: conceitos e temas. Rio de Janeiro: Bertrand Brasil, 1995.

GOTTMANN, J. Megalopolis or the Urbanization of the Northeastern Seaboard. Economic Geography, v. 33, n. 3, p. 189-200, jul. 1957.

HAESBAERT, R. Regional-Global: dilemas da região e da regionalização na geografia contemporânea. Rio de Janeiro: Bertrand, 2010.

. A noção de rede regional: reflexões a partir da "migração" gaúcha no Brasil. Território, v. 3, n. 4, p. 55-71, 1998.

Rio Grande do Sul: uma proposta de regionalização. Boletim Gaúcho de Geografia, Porto Alegre, v. 10, n. 1, 1983. 
HARVEY, D. A justiça social e a cidade. São Paulo: Hucitec, 1980.

KAYSER, B. A região como objeto de estudo da geografia. In: GEORGE, P. et al. (Org.). A geografia ativa. São Paulo: DEL, 1968.

; GEORGE, P. A região como objeto de intervenção. In: GEORGE, P. et al. (Org.). A geografia ativa. São Paulo: DEL, 1968.

LACOSTE, Y. A geografia: isso serve, em primeiro lugar, para fazer a guerra. Campinas-SP: Papirus, 1988.

LEFEBVRE, H. O direito à cidade. São Paulo: Centauro, 2001.

The Production of Space. New York: Blackwell, 1991.

La revolución urbana. Madrid: Alianza, 1972.

LENCIONI, S. Metropolização do espaço e a constituição de megarregiões. In: FERREIRA, A.; RUA, J.; MATTOS, R. C. (Org.). Desafios da metropolização do espaço. Rio de Janeiro: Consequência, 2015. p. 35-68.

O urbano-metropolitano: um desafio ao conhecimento e à governança. São Paulo, 2014. Mimeo.

. Redes, coesão e fragmentação do território metropolitano. Scripta Nova, Barcelona, v. XIV, n. 331, 2010.

. Impasses da gestão metropolitana nas regiões de Buenos Aires, São Paulo e Santiago.

Scripta Nova, Barcelona, v. XII, n. 270, 2008.

Condições gerais de produção: um conceito a ser recuperado para a compreensão das desigualdades de desenvolvimento regional. Scripta Nova, Barcelona, v. XI, n. 245, 2007.

Da cidade e sua região à cidade-região. In: SILVA, J.; LIMA, L.; ELIAS, D. (Org.).

Panorama da geografia brasileira I. São Paulo: Annablume, 2006a.

Memorial. Tese (Professora titular em Geografia) - Faculdade de Filosofia, Letras e Ciências Humanas, Universidade de São Paulo, São Paulo, 2006 b.

. Uma nova determinação do urbano: o desenvolvimento do processo de metropolização do espaço. In: CARLOS, A. F. A.; LEMOS, A. I. G. (Org.). Dilemas urbanos: novas abordagens sobre a cidade. São Paulo: Contexto, 2003. p. 35-44.

Região e geografia. São Paulo: Edusp, 1999a.

Região e geografia: a noção de região no pensamento geográfico. In: CARLOS, A. F. A. (Org.). Novos Caminhos da Geografia. São Paulo: Contexto, 1999b. p. 187-204.

. Reestruturação urbano-industrial: centralização do capital e desconcentração da Metrópole de São Paulo, a indústria têxtil. Tese (Doutorado em Geografia Humana) - Faculdade de Filosofia, Letras e Ciências Humanas, Universidade de São Paulo, São Paulo, 1991. 
Agricultura e urbanização: a capitalização no campo e a transformação da cidade - Jardinópolis: o estudo de um lugar. Dissertação (Mestrado em Geografia Humana) - Faculdade de Filosofia, Letras e Ciências Humanas, Universidade de São Paulo, São Paulo, 1985.

; CARLOS, A. F. Alguns elementos para a discussão do espaço geográfico como mercadoria. Borrador Teoria e Método, São Paulo, v. 1, p. 1-9, 1982.

LEOPOLDO, E. The space in transition: from urban-industrial economy to metropolitan-financial economy. In: MOORE CHERRY, N.; PIÑEIRA MARTIÑAN, M. J. (Org.). Addressing Complex Urban Challenges: social, economic and cultural transformations in the city. Santiago de Compostela: IDEGA/USC, 2015. p. 55-67.

MARTINS, J. S. Apresentação. In: MARTINS, J. S. (Org.). Henri Lefebvre e o retorno à dialética. São Paulo: Hucitec, 1996. p. 9-11.

O cativeiro da terra. São Paulo: Hucitec, 1986.

MARX, K. O capital: crítica da economia política. 2. ed. São Paulo: Nova Cultural, 1985. v. I.

MASSEY, D. Regionalism: some current issues. Capital and Class, v. 2, n. 3, p. 106-125, 1978.

OLIVEIRA, F. Elegia para uma re(li)gião: Sudene, Nordeste, planejamento e conflitos de classes. Rio de Janeiro: Paz e Terra, 1977.

SALGUEIRO, T. Tendências da urbanização em Portugal. In: SOUZA, M. A. (Org.). O mundo do cidadão, um cidadão do mundo. São Paulo: Hucitec, 1996. p. 139-148.

SANTOS, M. Por uma geografia nova: da crítica da geografia a uma geografia crítica. São Paulo: Hucitec, 1978.

A cidade nos países subdesenvolvidos. Rio de Janeiro: Civilização Brasileira, 1965.

SCOTT, A. et al. Cidades-regiões globais. Espaço \& Debates, São Paulo, n. 41, p. 11-25, 2001.

SEABRA, O. C. L. Geografia urbana que fazemos. Revista do Departamento de Geografia, São Paulo, p. 284-307, 2012. Volume especial RDG 30 anos.

- Metropolização: a reprodução do urbano na crise da sociedade do trabalho. Cidades, São Paulo, v. 6, n. 10, 2009.

. A insurreição do uso. In: MARTINS, J. S. (Org.). Henri Lefebvre e o retorno à dialética. São Paulo: Hucitec, 1996. p. 71-86.

A muralha que cerca o mar: uma modalidade de uso do solo urbano. Dissertação (Mestrado em Geografia Humana) - Faculdade de Filosofia, Letras e Ciências Humanas, Universidade de São Paulo, São Paulo, 1979.

SILVA, J. B. França e Escola Brasileira de Geografia: verso e reverso. Fortaleza: UFC, 2012.

SILVEIRA, M. L. O espaço geográfico: da perspectiva geométrica à perspectiva existencial. Geousp, São Paulo, n. 19, p. 81-91, 2006. 
SOJA, E. Para além da postmetropolis. Revista UFMG, Belo Horizonte, v. 20, n. 1, 2013. Regional Urbanization and the End of the Metropolis Era. In: BRIDGE, G.; WARSON, S. (Org.). The New Blackwell Companion to the City. New York: Blackwell, 2011. p. 679689.

VIDAL DE LA BLACHE, P. Princípios de geografia humana. Lisboa: Cosmos, 1954. 